MATEC Web of Conferences 47, 02001 (2016)

DOI: $10.1051 /$ matecconf/20164702001

(C) Owned by the authors, published by EDP Sciences, 2016

\title{
Impact Resistance of Recycled Aggregate Concrete with Single and Hybrid Fibers
}

\author{
Sallehan Ismail ${ }^{1, a}$ and Mahyuddin Ramli $^{2}$ \\ ${ }^{1}$ Faculty of Architecture, Planning and Surveying, Universiti Teknologi Mara, 32610 Seri Iskandar, Perak, Malaysia \\ ${ }^{2}$ School of Housing, Building and Planning, Universiti Sains Malaysia, 11800 Pulau Pinang, Malaysia
}

\begin{abstract}
This paper presents a recycled aggregate concrete (RAC) mix that has been modified by adding treated recycled concrete aggregate (RCA) and various types of fiber-reinforced systems. The effectiveness of these modifications in terms of energy absorption and impact resistance was evaluated and compared with that of the corresponding regular concrete, as well as with unmodified RAC specimens. Results clearly indicate that although modification of the RAC mix with treated RCA significantly enhances the impact resistance of RAC, further diversification with additional fiber, particularly those in hybrid form, can optimize the results.
\end{abstract}

\section{Introduction}

Recycling of concrete waste into recycled concrete aggregate (RCA) has been identified as a potential source of alternative aggregates to produce an environmentally benign concrete $[1,2]$. However, RCA cannot be simply applied in concrete production because its properties differ from those of natural aggregates. Several researchers [3-5] have found that complete or partial incorporation of RCA as a replacement for natural aggregates in recycled aggregate concrete (RAC) mixes can reduce the mechanical strength of the resulting concrete. Moreover, the presence of old cement mortar in RCA results in weakness in the interface zone between the new cement mortar and the aggregate, thereby crucially affecting the compressive strength of the RAC [6]. In recent years, many researchers have studied the behavior of RAC under static load. However, attempts to study RAC behavior under dynamic loads, such as impact loads, are seldom reported in the literature. In a research conducted by Rao et al. [7] on RAC under drop weight impact load, the impact resistance of RAC was found to decrease proportionally with the increase in RCA replacement level. Ismail and Ramli [8] observed that the impact resistance of RAC beams with treated RCA tends to improve slightly compared with that of RAC beams with untreated RCA. In practice, a concrete structure is designed with high impact resistance criteria to serve in areas subjected to high repeated impact loads, such as during an earthquake, missile impact and explosion, transportation and barrier structures subjected to vehicle crash impact, impact of water wave motions on offshore structure, rock falling and etc. Furthermore, high impact resistance concrete is essential in the production of structure piles, which are designed to sustain being repetitively subjected to impact loading during the pile driving process [9]. Understanding the behavior of concrete subjected under impact loading is important because this behavior differs from that of concrete under quasi-static loading [7].

\footnotetext{
${ }^{a}$ Corresponding author : salleh_itm@yahoo.com
} 
The present study mainly aims to evaluate the contributions of various fiber-reinforced systems in enhancing the energy absorption and/or impact resistance capacities of RAC beams. The mix proportion of RAC consisted of treated coarse RCA, as developed in our previous research [8]. This mix proportion can further diversify the RAC content through the inclusion of various fiber-reinforced systems. Two different types of synthetic fibers were selected (barchip and polypropylene fibers) and proposed to be added as single and hybrid forms at the appropriate dosage in a series of RAC mixes, respectively. This work is also interested to determine the most suitable fiber composition and the optimum amount of fiber that can significantly enhance the performance of RAC. The results of this study can illuminate the potential benefits of the proposed novel method to develop a comprehensive and systematic approach for RAC production.

\section{Experimental Program}

\subsection{Materials}

The cement used in the concrete mixtures in this study was ordinary Portland Cement Type I with a specific gravity of $3.15 \mathrm{~g} / \mathrm{cm}^{3}$. In this study, all of the coarse aggregates used had a maximum size of $20 \mathrm{~mm}$. The natural coarse aggregate used was crushed granite. The coarse RCA used was generated from waste concrete cube collected from the debris collection area. Jaw crushers were used to crush and break down concrete waste into small particle sizes. After crushing, the RCA was graded using a vibrator sieve to obtain aggregates with a maximum size of $20 \mathrm{~mm}$. Two types of coarse RCA were used in this study, treated and untreated. The treated RCA is prepared by modifying the RCA surface structure through the combination of two different surface treatment methods. In this process, the RCA is initially treated by soaking in hydrochloric $(\mathrm{HCl})$ acid at 0.5 molar $(\mathrm{M})$ concentration. They are then impregnated with wollastonite solution. The details on the materials and procedures involved in this treatment process were described in our previous research [8]. Table 1 provides a comparison of the properties of coarse natural aggregate (granite) and coarse treated and untreated RCA in terms of physical and mechanical strength characteristics. The natural fine aggregate or sand used in this study was uncrushed quartzite natural river sand which consisted of particles that passed through a sieve size of $5.00 \mathrm{~mm}$. Two synthetic fibers of different types and geometric properties were used: i) Barchip fiber type 54, which is manufactured in modified olefin synthetic fiber, was supplied by Elasto Plastic Concrete Inc. and ii) polypropylene fibers produced in fibrillated form, supplied by Timuran Engineering Sdn. Bhd. (Table 2). To enhance the workability of the concrete in this study, we used a chloride-free super plasticising admixture based on sulphonated naphthalene polymers.

Table 1. Properties of coarse aggregate [8].

\begin{tabular}{|l|c|c|c|c|}
\hline \multicolumn{1}{|c|}{ Properties of Aggregate } & $\begin{array}{c}\text { Sizes of } \\
\text { aggregate }\end{array}$ & $\begin{array}{c}\text { Natural } \\
\text { Granite }\end{array}$ & Untreated RCA & Treated RCA \\
\hline Particle Density - Oven Dry & $20 \mathrm{~mm}$ & 2.60 & 2.33 & 2.4 \\
$\left(\mathrm{Mg} / \mathrm{m}^{3}\right)$ & $10 \mathrm{~mm}$ & 2.58 & 2.23 & 2.3 \\
Water absorption (\%) & $20 \mathrm{~mm}$ & 0.60 & 4.44 & 3.71 \\
& $10 \mathrm{~mm}$ & 0.70 & 5.58 & 5.02 \\
Agg. crushing value (\%) & $14 \mathrm{~mm}$ & 24.32 & 29.15 & 28.34 \\
Agg. impact value (\%) & $14 \mathrm{~mm}$ & 13.98 & 21.78 & 19.26 \\
LA abrasion value (\%) & $14 \mathrm{~mm}$ & 34.76 & 39.12 & 36.76 \\
\hline
\end{tabular}




\subsection{Mix design}

The designated concrete mix proportions were based on a constant effective water/cement ratio of 0.41 for all concrete mixtures in accordance with the British method published by the Department of Environment [10] to achieve a target slump range of $30 \mathrm{~mm}$ to $60 \mathrm{~mm}$ and a compressive strength of $50 \mathrm{MPa}$ on 28 day. Nine series of mixtures were prepared depending on the type of coarse aggregate and the varying volume fraction of the fiber content, as follows : (i) $\mathrm{CO}$ - normal concrete; (ii) $\mathrm{RO}$ and TR - refer to RAC composed of untreated and treated coarse RCA, respectively; (iii) BF and PF RAC composed of treated coarse RCA and incorporated with single barchip and polypropylene fiber, respectively; and (iv) HB1, HB2, HB3 and HB4 - a group of RAC specimens composed of treated RCA and then incorporated with various fractions of fiber volume in hybrid combinations of barchip and polypropylene fiber.

The dosage compositions of the coarse aggregates in this experiment were kept constant by replacing the natural coarse aggregate with untreated or treated RCA at $60 \%$ of the weight of the total coarse aggregate content in all RAC mixtures. Meanwhile, the dosage designs of either individual or hybrid fibers added to the respective RAC mix were kept constant at a total volume fraction rate of $1.2 \%$ (by volume of cement). This parameter is selected on the basis of our previous research findings [11], in which a similar mix design was used to show that the inclusion of single barchip fiber at a volume fraction of $1.2 \%$ (by volume of cement) produces optimum compressive strength of RAC specimens at 28 days. The detailed mix design and proportions in the constituent materials for the overall concrete specimens are presented in Table 3.

\subsection{Concrete specimen preparation and curing}

All concrete mixes in this study were mixed in accordance to the sequence prescribed in BS1881-125 [12]. A drum mixer was used to prepare all the concrete mixes. For each concrete mix, $100 \mathrm{~mm}$ cubes were cast for the compressive strength test, $50 \times 100 \mathrm{~mm} \times 500 \mathrm{~mm}$ concrete plate were cast for impact resistance test and $100 \mathrm{~mm}$ x $100 \mathrm{~mm}$ x $500 \mathrm{~mm}$ prisms were cast for the flexural strength. All concrete specimens were cast in laboratory conditions, demolded at $24 \mathrm{~h}$ after casting, and then fully immersed in water at $25 \pm 2{ }^{\circ} \mathrm{C}$ until testing age were reached.

\subsection{Testing}

In this study, the effects of the results of engineering properties of different series modified RAC mix specimens were analyzed and compared with the corresponding to normal aggregate concrete (CO) and also with unmodified RAC specimens (RO) to determine their effectiveness. The parameters such as compressive and flexural strength of hardened concretes were examined at the age of 7, 28, 90, 180 days. The compressive strength test was conducted in compliance with BS EN 12390-3 [13]. Flexural strength test was conducted to measure the ability of a concrete beam to resist bending and the test procedure were performed in accordance to BS EN 12390-5 [14]. An impact resistance test was conducted to gain a better understanding of the load resistance and/or total energy absorption behaviour of concrete when subjected to impact loads. For this test the specimens prepared were in the form of rectangular plates with dimensions of $50 \mathrm{~mm} \times 100 \mathrm{~mm} \times 500 \mathrm{~mm}$. The input energy was provided by a steel ball weighing $450 \mathrm{~g}$, which was released and dropped from the cylindrical steel channel at a height of $800 \mathrm{~mm}$. The steel ball was dropped repeatedly till the ultimate failure of the test specimens. The detail of the instrument involve and test set up of impact resistance test should refer to the references [8]. The impact resistance of the concrete plates was determined by measuring the energy absorbed by the fracture of the specimen, which was impacted by a steel ball through a certain number of blows that cause its ultimate failure. The impact energy absorbed by specimens was calculated from the area under the impact load-deflection curve $[15,16]$ and was analyzed, moment by moment, after the steel ball was dropped. 
Table 2. Specification of barchip and polypropylene fibers.

\begin{tabular}{|l|c|c|}
\hline \multirow{2}{*}{\multicolumn{1}{|c|}{ Item }} & \multicolumn{2}{|c|}{ Specifications of fibers } \\
\cline { 2 - 3 } & Barchip & Polypropylene \\
\hline Average Length & $27^{ \pm} 2 \mathrm{~mm}$ & $15 \mathrm{~mm}$ \\
Tensile Strength & $640 \mathrm{MPa}$ & $45-60 \mathrm{ksi}$ \\
Average Diameter & $0.52 \mathrm{~mm}$ & - \\
Surface Texture & Continuously Embossed & - \\
No. Fibers per kg & 37,000 & - \\
Specific Gravity & $0.92 \mathrm{~g} / \mathrm{cm}^{3}$ & $0.9 \mathrm{~g} / \mathrm{cm}^{3}$ \\
Youngs Modulus & $10 \mathrm{GPa}$ & $0.5 \times 10 \mathrm{ksi}$ \\
Melting Point & $159^{\circ} \mathrm{C}-179^{\circ} \mathrm{C}$ & $160^{\circ} \mathrm{C}-170^{\circ} \mathrm{C}$ \\
Ignition Point & Greater than $450^{\circ} \mathrm{C}$ & $590^{\circ} \mathrm{C}$ \\
\hline
\end{tabular}

Table 3. Mix proportions.

\begin{tabular}{|c|c|c|c|c|c|c|c|c|c|}
\hline \multirow{3}{*}{ Specimen } & \multirow{3}{*}{$\underset{\mathrm{kg} / \mathrm{m}^{3}}{\text { Cement }}$} & \multirow{3}{*}{$\begin{array}{l}\text { Water } \\
\mathrm{kg} / \mathrm{m}^{3}\end{array}$} & \multirow{2}{*}{\multicolumn{2}{|c|}{$\begin{array}{c}\text { Coarse } \\
\text { aggregate } \mathrm{kg} / \mathrm{m}^{3}\end{array}$}} & \multirow{3}{*}{$\begin{array}{l}\text { Sand } \\
\mathrm{kg} / \mathrm{m}^{3}\end{array}$} & \multirow{3}{*}{$\begin{array}{l}\text { SP } \\
(\%)\end{array}$} & \multicolumn{2}{|c|}{ Vol. fraction of fiber (\%) } & \multirow{3}{*}{$\begin{array}{c}\text { Total vol. } \\
\text { fraction } \\
\text { of fiber } \\
\%\end{array}$} \\
\hline & & & & & & & \multirow[t]{2}{*}{ Barchip } & \multirow{2}{*}{ Polypropylene } & \\
\hline & & & Gravel & RCA & & & & & \\
\hline $\mathrm{CO}$ & 512 & 210 & 956 & - & 722 & 0 & - & - & - \\
\hline RO & 512 & 210 & 382 & 574 & 722 & 0 & - & - & - \\
\hline TR & 512 & 210 & 382 & 574 & 722 & 0.2 & - & - & - \\
\hline $\mathrm{BF}$ & 512 & 210 & 382 & 574 & 722 & 0.3 & 1.2 & - & 1.2 \\
\hline $\mathrm{PF}$ & 512 & 210 & 382 & 574 & 722 & 0.3 & - & 1.2 & 1.2 \\
\hline HB1 & 512 & 210 & 382 & 574 & 722 & 0.3 & 0.96 & 0.24 & 1.2 \\
\hline HB2 & 512 & 210 & 382 & 574 & 722 & 0.3 & 0.72 & 0.48 & 1.2 \\
\hline HB3 & 512 & 210 & 382 & 574 & 722 & 0.3 & 0.48 & 0.72 & 1.2 \\
\hline HB4 & 512 & 210 & 382 & 574 & 722 & 0.3 & 0.24 & 0.96 & 1.2 \\
\hline
\end{tabular}

\section{Results and Discussions}

\subsection{The mechanical properties of modified RAC}

The mechanical properties namely bulk density, compressive strength and flexural strength of normal concrete, unmodified and modified recycled aggregate concrete are presented in Table 4. Among all the concrete specimens, the reference concrete (CO) produces the greatest density. Its average bulk densities fall within $2400 \mathrm{~kg} / \mathrm{m}^{3}$, which is considered to meet the mix design target satisfactorily. By contrast, the inclusion of the RCA at $60 \%$ replacement of natural coarse aggregate results in the lowering of the density of concrete. The lower density of concrete mixes that contain the RCA is caused by the lower particle density of the RCA than the natural coarse aggregate. The results indicate that effect of the modification on the RAC mix by including the treated coarse RCA is significant in enhancing the engineering properties of RAC. However, further extending the diversity of the production RAC mix by adding fiber, particularly in its hybrid form, can optimize the results. As the results show, the optimum compressive strength is obtained by modified RAC in types HB4, whose produce the highest compressive strength performance compared with those of other specimens, particularly at the long-term curing ages. The results also confirm that modifying RAC using treated RCA and inclusion of single and hybrid fiber found significantly the contribute to the gain in optimum flexural strength. The gain in flexural strength of the specimens with hybrid fiber under the respective curing age is not as obvious as that of the single-fiber specimens. However, using hybrid fiber is found to be beneficial for resisting the flexural load when specimens are exposed to a longer curing period. This result may suggest that the dispersion of different types of fiber strengthens the bond 
between fibers, and with the cement matrix occurrence, the RAC specimens benefit by reinforcing the effects of hybridisation that can resist and bridge the cracks [17, 18].

Table 4. Mechanical properties of modified RAC.

\begin{tabular}{|c|c|c|c|c|c|c|c|c|c|}
\hline \multirow{3}{*}{ Specimen } & \multirow{3}{*}{ Density at 28 days $\left(\mathrm{kg} / \mathrm{m}^{3}\right)$} & \multirow{2}{*}{\multicolumn{4}{|c|}{$\begin{array}{c}\text { Compressive strength (MPa) } \\
\text { Age at testing (days) }\end{array}$}} & \multirow{2}{*}{\multicolumn{4}{|c|}{$\begin{array}{c}\text { Flexural strength (MPa) } \\
\text { Age at testing (days) }\end{array}$}} \\
\hline & & & & & & & & & \\
\hline & & 7 & 28 & 90 & 180 & 7 & 28 & 90 & 180 \\
\hline $\mathrm{CO}$ & 2400 & 45.13 & 54.54 & 58.54 & 62.34 & 3.86 & 5.3 & 5.91 & 6.27 \\
\hline RO & 2346 & 37.31 & 46.98 & 52.24 & 57.37 & 3.73 & 4.65 & 5.31 & 5.45 \\
\hline TR & 2370 & 46.61 & 52.18 & 57.8 & 60.98 & 3.69 & 4.83 & 5.75 & 5.97 \\
\hline BF & 2356 & 48.82 & 56.13 & 63.61 & 66.64 & 4.92 & 5.48 & 6.47 & 6.71 \\
\hline $\mathrm{PF}$ & 2352 & 49.45 & 52.02 & 58.89 & 68.45 & 4.56 & 5.38 & 5.84 & 6.33 \\
\hline HB1 & 2354 & 46.15 & 53.83 & 65.6 & 69.65 & 5.18 & 5.35 & 5.56 & 6.49 \\
\hline HB2 & 2355 & 49.69 & 53.76 & 61.28 & 66.01 & 4.90 & 5.25 & 5.62 & 6.23 \\
\hline HB3 & 2354 & 48.84 & 52.33 & 64.42 & 65.41 & 4.87 & 5.04 & 5.52 & 6.53 \\
\hline HB4 & 2348 & 46.86 & 53.22 & 69.28 & 69.90 & 4.58 & 5.05 & 5.79 & 6.25 \\
\hline
\end{tabular}

\subsection{Impact resistance}

The response of all specimens subjected to low-velocity impact loading at ages of 28, 90, and 180 days is plotted in Figures 1. It can seen that the impact energy absorbed by respective specimens at the first crack and at ultimate failure is varied. Investigation of the impact resistance performance of specimens at 28 days shows that the RO specimens present minimal results, followed by the TR specimens. By contrast, the PF specimens demonstrate the highest impact resistance which is approximately $56 \%$ higher than that of the $\mathrm{CO}$ specimens. These are followed by HB1, H2, BF, HB4, and HB3, which have total impact energy values of approximately $45 \%, 42 \%, 34 \%, 30 \%$, and $29 \%$, respectively, higher than those of the $\mathrm{CO}$ specimens. The prolonged curing exposure generally results in an increase in the impact resistance of all specimens. However it could notice that at 90 and 180 days, the impact resistance of the RO specimens on both testing ages is still the lowest, whereas that of the TR specimens is slightly higher than that of the RO specimens. As expected, the impact resistance of the RAC specimens benefited from the reinforcing effect of fiber. This finding is confirmed by the better rate gain in impact energy of the plain concrete at first cracks. Ultimate failure was observed in all RAC specimens that consist of fibers at 90 and 180 days. Additionally, the data plotted in Figure 2 reveal that the maximum gain in total energy is highly present in hybrid fiber specimens, which are HB2 specimens for testing age of 90 days and HB1 specimens for testing age of 180 days.

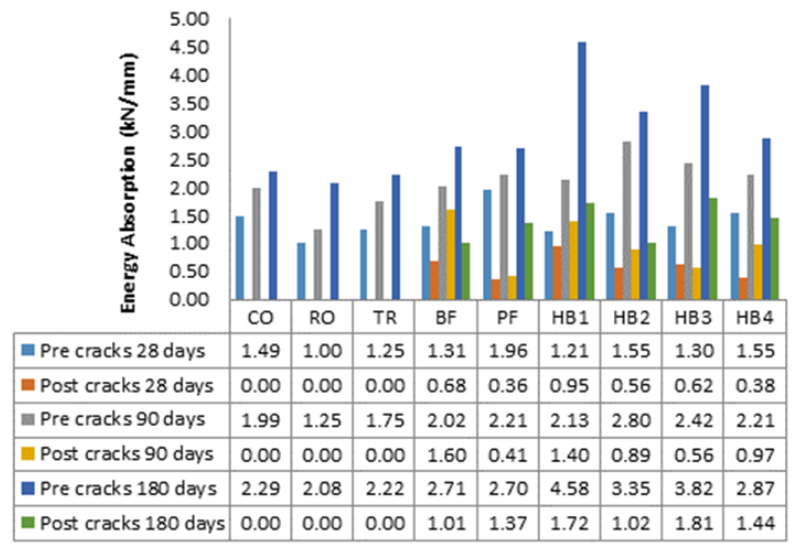

Figure 1. Pre-crack and post-crack energy absorption of all specimens exposed at various testing ages. 


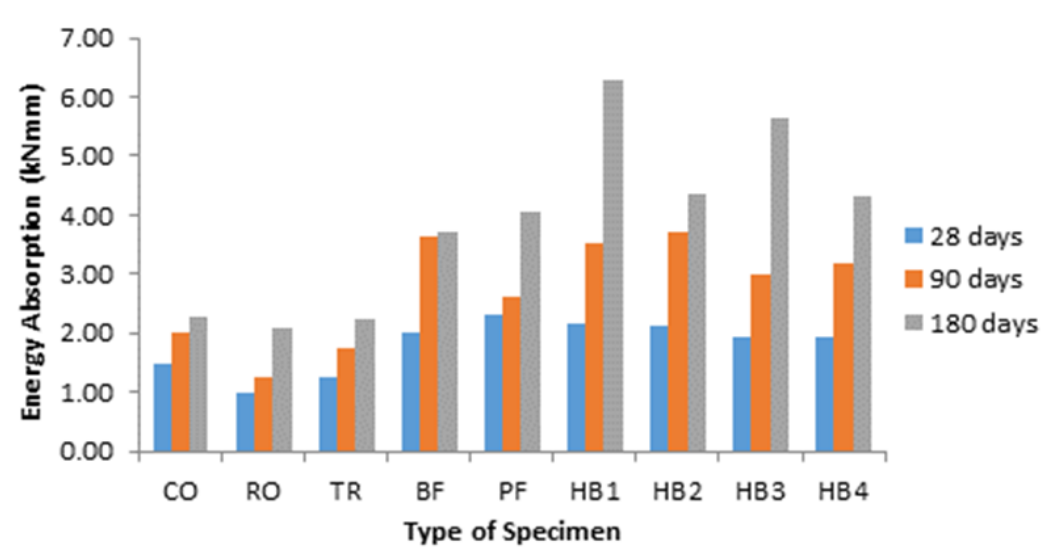

Figure 2. Total energy absorption of all specimens at various age.

Overall, the stiffness of the material is significantly related to the impact resistance of concrete [7, 15] because coarse aggregates are considered dominant constituents of materials during the formation of the final concrete structure. As shown in Table 1, the impact value of the RCA is less than that of natural coarse aggregates. Thus, RCA contributes to reducing the mechanical strength and modulus of elasticity of concrete. In addition, the weak interface between the aggregates and the cement paste may contribute to fracture propagation in the concrete [7]. By contrast, the resistance of concrete to crack propagation under an impact force is enhanced, as indicated in the TR concrete specimens. This phenomenon could be attributed to the improvement of the properties of the RCA and the modification that strengthened the interface between the aggregate-paste bond as a result of surface treatment.

Meanwhile, the most significant property required by a material subjected to impact loading is its energy-absorbing capability. The inclusion of randomly distributed fibers can enhance the toughness and ductility of concrete $[19,20]$. Accordingly, based on the data results, the impact resistance of RAC can substantially increase with the addition of randomly distributed fibers. The results suggest that the inclusion of single and/or hybrid fibers into the mixtures results in a conclusive increase of the capability of impact energy absorbed by specimens at first and ultimate cracking. By contrast, in the case of non-fibrous specimens ( $\mathrm{CO}, \mathrm{RO}$, and $\mathrm{TR}$ ), the improvement in post-crack resistance was negligible. As observed during testing, the ultimate failure on most of the non-fibrous specimens simultaneously occurred once the first visible crack formed during testing. This observation suggests that the fracture of non-fibrous concretes may suddenly occur because of its brittle behavior. Incorporating different volume ratios of barchip and polypropylene fibers in hybridization formation, such as into the HB1 specimens, is significant in increasing the ductility performance. The capability of fibrous specimens to absorb energy prior to impact loading suggests that the presence of fiber function delays the ultimate failure $[9,19,20]$.

\section{Summary}

The inclusion of treated RCA rather than untreated RCA in RAC specimens may enhance impact resistance. However, the RAC mix diversified with incorporated fibers exhibits higher impact resistance than the non-fibrous specimens. Among the specimens, the total energy absorbed by the modified RAC mix in type HB1 specimens reveals that they exclusively attained the highest value, and these values are estimated to be nearly three times more than those of the CO specimens, particularly in the later testing period after prolonged curing exposure. 


\section{References}

[1] A. Rao, K.N. Jha and S. Misra, Use of aggregates from recycled construction and demolition waste in concrete, Resources, Conservation and Recycling, 50(1), 71-81, (2007).

[2] S. Ismail, K.W. Hoe and M. Ramli, Sustainable Aggregates: The potential and challenge for natural resources conservation, Procedia-Social and Behavioral Sciences, 101, 100-109, (2013).

[3] S. Ismail, K.W. Hoe and M. Ramli, Influence of amount of recycled coarse aggregates and production process on properties of recycled aggregate concrete, Cement and Concrete Research, 37(5), 735-742, (2007).

[4] S. Ismail and M. Ramli, Engineering properties of treated recycled concrete aggregate (RCA) for structural applications, Construction and Building Materials, 44, 464-476, (2013).

[5] Ö. Arı̈̈z, A. Özsoy and G. Y1lmaz, Concrete with recycled aggregate, Key Engineering Materials, 264-268, 2145-2148, (2004).

[6] V.W.Y. Tam, X.F. Gao and C.M. Tam, Microstructural analysis of recycled aggregate concrete produced from two-stage mixing approach, Cement and Concrete Research, 35(6), 1195-1203, (2005).

[7] R.M. Chakradhara, S.K. Bhattacharyya and S.V. Barai, Behaviour of recycled aggregate concrete under drop weight impact load, Construction and Building Materials, 25(1), 69-80, (2011).

[8] S. Ismail and M. Ramli, Mechanical strength and drying shrinkage properties of concrete containing treated coarse recycled concrete aggregates, Construction and Building Materials, 68, 726-739, (2014).

[9] W.H. Kwan, M. Ramli and C.B. Cheah, Flexural strength and impact resistance study of fibre reinforced concrete in simulated aggressive environment, Construction and Building Materials, 63(1), 62-71, (2014).

[10]D.C. Teychenne, R.E. Franklin, H.C. Erntroy, D.W. Hobbs and B.K. Marsh, Design Of Normal Concrete Mixes, Building Research Establishment, Watford, United Kingdom, (1997).

[11]S. Ismail and M. Ramli, Effects of adding fibre on strength and permeability of recycled aggregate concrete containing treated coarse RCA, Int. J. of Civil, Architectural, Structural and Construction Engineering, 8(8), 890-896, (2014).

[12]BS 1881-Part 125, Testing Concrete, Methods for Mixing and Sampling Fresh Concrete in The Laboratory, British Standards Institution, London, United Kingdom, (1986).

[13]BS 1881-Part 125, Testing Hardened Concrete, Compressive Strength of The Test Specimens, British Standards Institution, London, United Kingdom, (2009).

[14]BS 1881-Part 125, Testing Hardened Concrete, Flexural Strength of The Test Specimens, British Standards Institution, London, United Kingdom, (2009).

[15]M.M. Al-Tayeb, B.H. Abu Bakar, H. Ismail and H.M. Akil, Effect of partial replacement of sand by recycled fine crumb rubber on the performance of hybrid rubberized-normal concrete under impact load: experiment and simulation, J. of Cleaner Production, 59, 284-289, (2013).

[16]N. Banthia, P. Gupta and C. Yan, Impact resistance of fiber reinforced wet-mix shotcrete part 1: beam tests, Materials and Structures, 32(8), 563-570, (1999).

[17]C.X. Qian and P. Stroeven, Development of hybrid polypropylene-steel fibre-reinforced concrete, Cement and Concrete Research, 30(1), 63-69, (2000).

[18]K. Ramadevi and D.L.V. Babu, Flexural behaviour of hybrid (steel-polypropylene) fibre reinforced concrete beams, European J. of Scientific Research, 70(1), 81-87, (2012).

[19]M. Nili and V. Afroughsabet, The effects of silica fume and polypropylene fibers on the impact resistance and mechanical properties of concrete, Construction and Building Materials, 24(6), 927-933, (2010).

[20]S. Erdem, A.R. Dawson and N.H. Thom, Microstructure-linked strength properties and impact response of conventional and recycled concrete reinforced with steel and synthetic macro fibres, Construction and Building Materials, 25(10), 4025-4036, (2011). 